\title{
Desarrollo y bienestar infantil relacional
}

\author{
Margarita Olivas Payan \\ Universidad Autónoma de Ciudad Juárez, México. \\ mopayan@prodigy.net.mx \\ https://orcid.org/0000-0002-1861-0355
}

Recibido: 1 de julio de 2020

Aceptado: 31 de setiembre de 2020

Resumen: Esta investigación es parte de una tesis doctoral, cuyo objetivo consistió en identificar las redes y sus relaciones movidas por sujetos, niños y adultos, para configurar el desarrollo y el bienestar. Es decir, en las políticas de infancia dirigidas a ellos, se intercambian bienes relacionales que son de interés para esta investigación. La estrategia metodológica para el presente estudio fue la etnografía, misma herramienta que ayudó a entrar en el mundo de los niños y conocer su agencia. En este espacio de relaciones interactúan dos sistemas: micro y macro, el micro es donde las relaciones primarias son trastocadas y el macro donde la instrumentalización es una condición, ambos dan lugar al nacimiento del sistema meso como un espacio donde las redes se complejizan y la contingencia da lugar a la informalidad. En estos sistemas intervienen redes de actores movidas por sujetos cuyo intercambio simbólico es el desarrollo y bienestar, de ahí que, el cambio social cobre sentido. Dentro de estos hallazgos la participación infantil es visible.

Palabras claves: Desarrollo; bienestar, políticas sociales; infancia; ciudadanía.

\section{Relational child development and well-being}

\section{(c) (i) (9)}

La Revista Estudios es editada por la Universidad de Costa Rica y se distribuye bajo una Licencia Creative Commons Atribución-NoComercial-CompartirIgual 3.0 Costa Rica. Para más información envíe un mensaje a revistaestudios.eeg@ucr.ac.cr. 
Dossier: V Simposio Internacional y IX Nacional sobre Derechos de la Niñez y la Adolescencia

Abstract: This research is part of a Ph.D. thesis, whose objective is to identify the networks and their relationships moved by subjects, children and adults, to configure development and well-being. In other words, in childhood policies aimed at them, relational goods that are of interest to this research are exchanged. The approach method for the present study was ethnography, the same tool that helped to understand the children's environment and learn about their agency. In this space two systems interact: micro and macro, the micro is where the primary relationships are disrupted and the macro where instrumentalization is a condition, both give place to the meso system as a space where the networks become more complex and the contingency gives rise to informality. In these systems, other actor's networks intervene moved by subjects whose symbolic exchange is development and wellbeing, hence, social change makes sense. Within these findings, children's participation is visible.

Keywords: Development; welfare, social policies; childhood; citizenship.

\section{Introducción}

El gran debate teórico en torno a la Convención Internacional de los Derechos del Niño, de ahora en adelante CDN, conlleva una serie de transformaciones culturales, sociales y políticas en la mayor parte de los países. Con estos hallazgos se observa la discontinuidad de los valores del bienestar en las instituciones, donde los símbolos llevan a los sujetos niños atribuirles nuevo significado a esas relaciones. Porque es ahí donde se intercambian bienes, lo que para los niños es un derecho y una obligatoriedad del estado, para ellos este espacio se traduce en una oportunidad de socialización con sus pares.

Lo anterior indica que si bien la pedagogía, la psicología y la pediatría han contribuido a producir un aval de conocimientos sobre este importante y decisivo periodo en la vida del ser humano, también lo han hecho en la configuración del desarrollo infantil con parámetros universales. Sin embargo, existe la necesidad de integrar otras diciplinas para incrementar la discusión teórica sobre este principio ciudadano, como lo es la CDN. En esta discusión deben estar presente la voz de los niños quienes crean y recrean su mundo con sus propias percepciones de las

\section{(C) $(0 \bigcirc)$}

La Revista Estudios es editada por la Universidad de Costa Rica y se distribuye bajo una Licencia Creative Commons Atribución-NoComercial-CompartirIgual 3.0 Costa Rica. Para más información envíe un mensaje a 
Dossier: V Simposio Internacional y IX Nacional sobre Derechos de la Niñez y la Adolescencia políticas dirigidas a ellos, de ahí que, se requieran nuevas miradas epistemológicas que cuestionen el desarrollo infantil en un mundo global con serios contrastes sociales.

Otra categoría de interés es la infancia, la cual es analizada en este estudio en conjunto con el concepto de ciudadanía, por ello, se integra el discurso de los niños como agentes sociales competentes para configurar el bienestar. Que, si bien participan otros actores como el estado, la familia, el mercado y la sociedad civil, ellos son quienes a través de sus prácticas sociales cambian y configuran el bienestar infantil. La fotografía fue en su momento una herramienta para el levantamiento de datos y dar soporte a estos resultados. Además, es pertinente señalar cómo a través de estas prácticas que estos actores realizan, subestiman muchas de las veces las capacidades del niño para expresar, discutir y aportar sus propias visiones sobre los derechos. Estos resultados aquí expuestos pueden contribuir a trasformar los espacios de expresión e integrar a otros actores para dimensionar lo social como una red de redes, lo que obliga, hacerla tangible a través de la voz de diversos participantes. Cabe señalar en que en este ensayo se analiza únicamente el discurso infantil.

No obstante, cabe reconocer que, los procesos para la trasformación de un estado de bienestar a un estado de derechos, obliga a las instituciones que tradicionalmente fueron en su momento identificadas como protectoras, deben trasformar sus espacios y valores donde se otorgan beneficios que son derechos con obligatoriedad, para reconstruir la autonomía del sujeto niño. Por lo tanto, los colectivos infantiles generalmente se les caracteriza como minorías en proceso de desarrollo y en situación marginal dentro de un entramado de relaciones significativas desde la estructura del estado para otorgar bienestar. Sobre esa base, se requiere de nuevas discusiones teóricas que den cuenta de los procesos en los cuales el bienestar es propiamente un derecho para el desarrollo de su autonomía,

\section{(c) (i) (2)}

La Revista Estudios es editada por la Universidad de Costa Rica y se distribuye bajo una Licencia Creative Commons Atribución-NoComercial-CompartirIgual 3.0 Costa Rica. Para más información envíe un mensaje a 
Dossier: V Simposio Internacional y IX Nacional sobre Derechos de la Niñez y la Adolescencia

o bien la naturalización del desarrollo conduce a la instrumentalización y naturalización del propio desarrollo.

Es así, como en el contexto de estas discusiones y en todos los ámbitos en que está presente el niño, uno de los cuestionamientos para su reflexión es el rol de ciudadano en formación, en el cual, aparece el reconocimiento como sujeto receptor de derecho, con derechos de acción y no de reacción, este rol conduce muchas de las veces a una posición de minoría dentro de la estructura estatal, negando su voz.

\section{Desarrollo y bienestar Infantil relacional}

El estudio de la infancia como categoría social no es nuevo, pero muy recientemente ha empezado a ser un tema de interés para la sociología, la cual, busca su propia identidad como subdisciplina dentro de esta diciplina, otorgándole el estatus de sociología de la infancia, así lo sostiene Gaitán (2006, p. 17), quien en su breve análisis menciona que a partir de la CDN un grupo de sociólogos se han dado a la tarea de otorgar voz a los niños a través de sus trabajos y dentro de estas tendencias sobresalen tres enfoques teóricos:

a) El enfoque estructural, donde los niños son co_contructores de la sociedad, ellos también participan en su configuración y de la cual ellos forman parte, no como hecho biológico, pero si como parte de la familia, y su dependencia repercute en su invisibilidad debido a que son estudios mayormente a nivel macro, con apoyo de estudios demográficos y la sociología estadística.

b) Enfoques construccionistas define a la infancia como una construcción social y la etnografía es la metodología más adecuada para el estudio, ya que, las relaciones de los niños deben estudiarse en sus propias dimensiones a nivel micro, ellos participan en la construcción de su agencia.

c) Enfoque relacional define a la infancia como un proceso, el cual lo sitúa como relaciones complejas. El conocimiento se adquiere a través de los niños para reconocer sus derechos, ellos son definidos como seres individuales con un

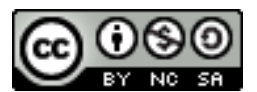

La Revista Estudios es editada por la Universidad de Costa Rica y se distribuye bajo una Licencia Creative Commons Atribución-NoComercial-CompartirIgual 3.0 Costa Rica. Para más información envíe un mensaje a revistaestudios.eeg@ucr.ac.cr. 
Dossier: V Simposio Internacional y IX Nacional sobre Derechos de la Niñez y la Adolescencia

peso social y participantes competentes en un mundo compartido por los adultos.

Esta clasificación revela que, a partir de la CDN, el derecho a la participación entra en conflicto con el concepto de ciudadanía, a este respecto Mayall (2002, p. 245) sostiene que el concepto de infancia es relacional, porque son los adultos quienes definen y priorizan unas políticas en relación con otras, determinando las necesidades que se establecen en esa relación, señalándolos como adultos del mañana y no del presente, estereotipo que la misma sociedad reproduce. En cambio, Donati (1993, p. 43), quien es uno de los autores de la sociología relacional y funge como académico en la catedra de sociología de la Universidad de Bolonia, argumenta que, la perspectiva relacional indica el inicio de una nueva época del pensamiento sociológico, no propiamente posmoderno, en parte porque ya no es posible hablar de necesidades sino de contingencias, donde la explicación y la comprensión están siendo rebasadas por el movimiento que la misma sociedad está experimentando. El enfoque teórico, que postula este autor, es una teoría que centra su análisis en el carácter de las relaciones entre sujetos dentro de un contexto determinado, mismas que dan lugar a varias dinámicas e interacciones sociales, dentro de las cuales, la emergencia es una cualidad que puede explicar los cambios alrededor del fenómeno social en estudio. Es decir, normalmente tiene una estructura de redes, lo que conlleva a tensiones y conflictos relacionales, las cuales crean contingencias que no estaban determinadas a priori. Lo anterior se da, porque en dicho intercambio se comparten "bienes relacionales" que se producen y se comparten por los agentes sociales que ahí participan. Es por ello, que las redes informales tienen interés para este autor, ya que ahí se producen bienes relacionales primarios que gradualmente se convierten en cambios sociales.

A este respecto, Lazares (1996) sostiene, que la teoría de redes es deudora de diversas corrientes de pensamiento. Pero, en su argumento tiende a ser más incluyente y la describe como: "un conjunto bien delimitado de actores, individuos, 
Dossier: V Simposio Internacional y IX Nacional sobre Derechos de la Niñez y la Adolescencia

grupos organizados, comunidades, sociedades globales vinculadas unas a otras a través de una relación o un conjunto de relaciones sociales" (pág. 108) donde los actores sociales suelen ser individuos, empresas y unidades colectivas. Sus lazos relacionales se expresan a través de vínculos entre los actores que pueden estar integrados por diadas, triadas o bien grupos. Su contenido suele ser la substancia relacional, esto es, afecto, bienes, o dinero que constituyen la materialidad social de dicha relación. Sin embargo, hasta hoy las dos modalidades que mayormente han dado lugar a su propuesta son el enfoque estructural y el de acción, que para el autor, la sociología relacional que el propone es un enfoque alternativo para estudiar la sociedad y las nuevas formas de relacionarse.

Donati (1993) refiere que, no hay cambio social cuando las relaciones propias de una entidad social se construyen con cualidades distintivas, que no propiamente difieren de la procedente, o bien evolucionan, es concretamente el ordenar diferente los elementos que la integran (p.42). A mi entender, ciudadanía infantil, derechos, relaciones sociales, requieren un orden distinto para pensarlo en este nuevo siglo. Este principio del autor mantiene una asociación con la teoría de los lazos débiles propuesta por Granovetter M. (2000, p.46) que recomienda la importancia de estudiar los vínculos débiles en el enfoque de redes, mismos que aparecen mayormente en la interacción de un sistema micro y un sistema macro. El interés de estos vínculos es que en el uso de lazos débiles están los agentes con escasos lazos y privados de la información que acceden a limitadas noticias, donde sus normas, leyes y principios están acotados por su alta movilidad producto de la sobrevivencia. En este caso, los niños participan dentro de estos entramados que tienen sentido para su desarrollo y bienestar infantil. Para este autor, los niños entre más pequeños, más limitados tienen sus vínculos sociales, dicha afirmación entra en discusión por la complejidad misma de las relaciones en que se insertan las políticas dirigidas a ellos.

\section{(c) (i) (-)}

La Revista Estudios es editada por la Universidad de Costa Rica y se distribuye bajo una Licencia Creative Commons Atribución-NoComercial-CompartirIgual 3.0 Costa Rica. Para más información envíe un mensaje a 
Dossier: V Simposio Internacional y IX Nacional sobre Derechos de la Niñez y la Adolescencia

El desarrollo infantil temprano es un proceso de cambio donde el niño aprenden a dominar niveles siempre más complejos de movimiento, pensamiento, sentimientos y relaciones con los demás. Este periodo abarca el embarazo, puerperio, educación inicial y periodo preescolar, por lo tanto, intervienen toda una gama de disciplinas y actores sociales que brindan bienestar para que dicho desarrollo se genere en forma “integral y armónica". Es decir, el desarrollo biológico como categoría de análisis ha estado rodeada de postulados de la psicología del desarrollo y de la pedagogía, no obstante, la globalización de la economía, los tratados internacionales, la misma CDN, crean códigos relacionales que brinde respuesta a la complejidad misma de las sociedades. En efecto, la teoría relacional descrita por Donati (1993) otorga importancia a las redes informales, no deja fuera las redes estructurales, al contrario, participa en el resurgimiento de nuevas redes a partir de la interacción con el sistema estructural, pero resurge el sujeto que participa en la configuración de lo social, esto es en parte por, la emergencia de relaciones distintas que viven bajo la improbabilidad (p.47).

Es así, como la primera infancia se convierte en un periodo del desarrollo institucionalizado de lo biológico y por la psicología evolutiva y refrendado por las políticas de infancia, o bien, la representación por colectivos infantiles que tienen participación en la configuración de su desarrollo. El desafío aparece cuando los sistemas complejos propician contingencias que generan un conjunto de códigos simbólicos que son de interés para esta investigación. La tesis que se presenta a continuación afirma que el desarrollo y el bienestar infantil es relacional, dichas relaciones se vuelven más complejas en la medida que participan más actores y agentes sociales diversos, en un espacio determinado, dentro de los cuales están presente los niños. Por ello, el enfoque relacional resulta ser la mejor opción para una aproximación al conocimiento y explicación de estos fenómenos, debido a que las familias crean redes para la obtención de beneficios, debido a la sobrevivencia.

\section{(c) (i) (-)}

La Revista Estudios es editada por la Universidad de Costa Rica y se distribuye bajo una Licencia Creative Commons Atribución-NoComercial-CompartirIgual 3.0 Costa Rica. Para más información envíe un mensaje a 
Dossier: V Simposio Internacional y IX Nacional sobre Derechos de la Niñez y la Adolescencia

\section{Objetivos:}

1. Identificar las redes de relaciones para configurar el desarrollo y el bienestar infantil relacional en una comunidad, en la que diversos agentes generan cambios como fruto de las interacciones sociales.

2. Argumentar a partir de este enfoque relacional la configuración de la primera infancia en la construcción del sujeto como un agente social competente en una relación bilateral en conjunto con los adultos que cuidan de él.

\section{Estrategia metodológica:}

La etnografía aparece como una perspectiva epistemológica coherente para esta investigación, en parte, porque permite elaborar una representación coherente con lo que piensan y dice los sujetos. Por consiguiente, el investigador define su marco teórico, así lo menciona Guber, R. (2011, p, 44) en su obra "La Etnografía" y argumenta que en el trabajo de campo los actores son privilegiados por que expresan su cotidianidad, le otorgan sentido a su acción y desafía la universalidad de los grandes paradigmas sociológicos. No obstante, Geertz (1987, p.32), enfatiza, la etnografía es una metodología y no una disciplina, por ello, el conjunto de técnicas que deben estar presente en este estudio consiste en la observación participante y la entrevista abierta, mismas que, permite realizar levantamiento de datos para describir los escenarios donde están presente los niños.

Definir una frontera entre la entrevista grupal con niños y las características de un grupo focal, implica reconocer que, es borrosa porque por un lado la entrevista grupal funge como escenario y dispositivo de producción del discurso infantil; y en otro aspecto, el grupo focal integra personas representativas en calidad de

\section{(c) (i)(2)}

La Revista Estudios es editada por la Universidad de Costa Rica y se distribuye bajo una Licencia Creative Commons Atribución-NoComercial-CompartirIgual 3.0 Costa Rica. Para más información envíe un mensaje a 
Dossier: V Simposio Internacional y IX Nacional sobre Derechos de la Niñez y la Adolescencia informantes claves alrededor de una temática propuesta por el investigador. Rodríguez (2006, p.85), destaca, los niños tienden a construir un discurso más fragmentado y las fronteras tienden a deslizarse a partir de los instrumentos que se utilizan para captarlo en estos grupos infantiles, ya que, las capacidades de los niños en tanto agentes sociales no pueden perder de vista que viven una infancia involucrados en una red de relaciones con los adultos, construidos en un proceso de socialización y desarrollo infantil. Por ello, ambas técnicas en este ejercicio de investigación tienen elementos comunes que fueron seleccionados para su implementación como lo son:

a) La construcción del escenario fue en el hábitat natural donde tenían lugar las políticas sociales dirigidas a las madres de los niños seleccionados para participar. La habilitación con mesas y sillas de preescolar fue la comunidad sociopolítica que define Cortina (1997, p.33). El primer grupo se realizó en espacio abierto en la parte trasera del Centro Comunitario Kilometro 20, de ahora en adelante CCKM20, alejado del ruido. El segundo grupo se realizó un mes después y en el mismo lugar.

b) El grupo de niños en calidad de informantes claves y organizado alrededor del tema, lo que representó la audiencia donde cada participante resultó estimulado por la presencia de los otros, hacia los cuales iba a orientar su acción.

c) Criterios de selección de los niños: Se informó previamente a las madres presentes en el programa donde asistía un mayor número de niños. La coordinadora de los programas infantiles aceptó su presencia en las sesiones, porque consideró que las madres no contaban con espacios o personas que los pudieran cuidar. Las madres aceptaron e invitaron a los niños a entrar al lugar donde se iba a realizar el ejercicio. La edad para participar se consideró de cuatro a seis años, esto les permite colorear imágenes, además que cuenta con

\section{(C) $(0 \odot$}

La Revista Estudios es editada por la Universidad de Costa Rica y se distribuye bajo una Licencia Creative Commons Atribución-NoComercial-CompartirIgual 3.0 Costa Rica. Para más información envíe un mensaje a 
Dossier: V Simposio Internacional y IX Nacional sobre Derechos de la Niñez y la Adolescencia una competencia más desarrollada en el lenguaje. Los sexos fueron equitativos, cuatro niños y cuatro niñas en cada uno de los grupos.

d) Selección y capacitación del personal que participa como apoyo: un facilitador del grupo, dos personas encargadas de la toma de notas y un observador (investigador). En el primer grupo se integró una pedagoga como facilitadora, una psicóloga en el área de registro y un observador. En el segundo grupo participó una trabajadora de la unidad que apoya en regulación escolar a niños como facilitadora de grupo, una madre de familia y un joven del grupo de danza para niños apoyaron en el área de registro, y un observador.

\section{La comunidad relacional}

El CCKM20, es uno de los 42 Centros comunitarios ubicados en polígonos de pobreza que el gobierno municipal administra y a través de estos implementa una serie de programas sociales. Su objetivo es la promoción de la organización comunitaria, reconstrucción del tejido social y la formación de ciudadanía. Esta unidad fue seleccionada por su ubicación estratégica, pues se encuentra en una zona que abarca las dos cualidades, urbana y semiurbana, hay escasez de servicios de infraestructura para la salud, la educación y servicios básicos. Esta unidad le otorga servicios a 27 colonias donde habitan 4.574 niñas y niños menores de 5 años, de los cuales, el $46.7 \%$ son de $0-2$ años; $53.3 \%$ de $3-5$ años y únicamente asisten a preescolar el $26 \%$ de acuerdo con registros del Instituto Nacional de Estadística y Geografía (INEGI,2010).

No obstante, debido a sus escases de recursos, se mantiene una alianza con los tres niveles de gobierno, sociedad civil e instituciones de enseñanza superior, quienes implementan un conjunto de proyectos dirigidos a las familias, adultos mayores, jóvenes y niños. Esto permite una mirada macro en políticas de bienestar infantil, por sus estructuras y efectos en su implementación. Además, en el contexto

\section{(C) $(\Theta \odot$}

La Revista Estudios es editada por la Universidad de Costa Rica y se distribuye bajo una Licencia Creative Commons Atribución-NoComercial-CompartirIgual 3.0 Costa Rica. Para más información envíe un mensaje a 
Dossier: V Simposio Internacional y IX Nacional sobre Derechos de la Niñez y la Adolescencia micro se puede observar cómo las familias diversas se incorporan y obtienen beneficios significativos que les permite crear otro tipo de vínculos simbólicos con el bienestar infantil. Algunos de estos servicios pueden comprender aprender un oficio con el cual pueda mejorar la economía del hogar, ayudar a otras mujeres para recibir otros beneficios como orientación psicológica, talleres de computación, venta de productos elaborados en el hogar, distribución en unidades de servicio y gestión de documentos de identidad para los mismos niños, entre otros.

En esta breve descripción del escenario, se identifican las mismas redes de relaciones que hace complejos a ambos sistemas. Por ello, centrar el análisis en la mirada del desarrollo y bienestar infantil implicó fijar el principio de una comunidad de relaciones sociales, hacer un recorrido periódico en las áreas donde están presente los niños de la primera infancia, observar donde juegan, cómo están equipados los espacios donde participan y crear un conjunto de viñetas con apoyo de la fotografía, para después establecer un diálogo con ellos. La fotografía, fue en su momento un instrumento elegible para propiciar la conversación con ellos, las imágenes ilustran los espacios donde ellos se recrean, si bien sus frases son cortas, se presentan fragmentadas por la capacidad limitada para entablar una plática fluida con sus pares, por ello, sus enunciados le otorgan valor a lo que ellos observan.

\section{Descripción del del discurso infantil de los participantes en los grupos (Las fotografías se encuentran al final en el apartado de anexos).}

1. Evelin: 5 años, no asiste a la escuela.

"Me gusta jugar en los toboganes. Yo tomo leche con chocomilk" (lo que contiene la despensa que recibe la madre, el chocomil hace referencia al chocolate en polvo)

2. Jocelin: 5 años, no asiste a la escuela.

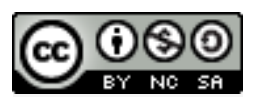

La Revista Estudios es editada por la Universidad de Costa Rica y se distribuye bajo una Licencia Creative Commons Atribución-NoComercial-CompartirIgual 3.0 Costa Rica. Para más información envíe un mensaje a revistaestudios.eeg@ucr.ac.cr. 
Dossier: V Simposio Internacional y IX Nacional sobre Derechos de la Niñez y la Adolescencia "Me gustan los columpios porque me dan mucho vuelo. Mi mamá me dice que haga caso" (Las reglas para el control dentro del CCKN20)

3. Osvaldo, 4 años, asiste a preescolar.

Yo conozco los juegos...es la escuela. El jugo es de naranja...cuando yo estuve enfermo de gripe" (identifica los juegos, el consultorio médico, el jugo de naranja que les integran a la despensa que ahí les otorgan)

4. Leslie, 4 años, asiste a preescolar

"Es donde trabaja la doctora" (identifica el consultorio)

5. Alim: 5 años, no asiste a la escuela

"Mi mamá me trae y me gusta jugar a los toboganes y juego. Yo tomo leche con chocomilk y meto las galletas...es donde está el doctor y nos sentamos mi mamá y yo" (identifica los juegos, el doctor, los alimentos que vienen en la despensa).

6. Brayan, 5 años, no asiste a escuela

"Si están allá los columpios...mi mamá me dice que le haga caso...y me deja jugar al resbaladero...y mi mamá viene a la leche y me la tomo en un vaso..., las mamás trabajan para sacar dinero y comprarnos cosas...todavía no como...porque a veces me dan. A veces no me dan...o me dan de comer sopa" (identifica los juegos, disciplina, alimentos).

7. Rosa, 5 años, no asiste a la escuela

"Yo conozco los columpios...a mi me dan frijoles con huevo y están muy ricos...es donde acuestan a uno, nos pican y curan" (los juegos, el consultorio médico, los alimentos)

8. Julia, 5 años, no asiste a la escuela

"Me gustan los columpios y los libros...es la doctora" (juegos, biblioteca infantil móvil, médico). 
Dossier: V Simposio Internacional y IX Nacional sobre Derechos de la Niñez y la Adolescencia

9. Kevin, 6 años, asiste a la escuela.

"Desayunando... una mesa y unas sillas...están en la plática de la leche. Está pesada y no la puede. Se están columpiando". (los alimentos, la sala de sesiones educativas, los juegos).

10. Brayan, 6 años. Preescolar.

"El seguro popular de la escuela, está bailando...están abrazando a su hijo". (los servicios de salud, las sesiones de danza de niños mayores, las sesiones educativas de la madre controlando a los más pequeños).

11. Elías, seis años, asiste a preescolar

"Está bailando, es el seguro popular" (las sesiones de baile, los servicios de salud).

12. Melania, seis años, preescolar.

"Están pegando...están haciendo ejercicio...es el doctor" (la disciplina, las sesiones de danza de los niños más grandes, el consultorio).

13. Estrella, seis años, preescolar

"El centro comunitario...están recogiendo la leche...están jugando los niños...no golpear para que los niños estén sanos y fuertes" (los pasillos del centro comunitario, la despensa, los juegos, la disciplina).

14. Kevin A. seis años, preescolar

"Los acompañan sus papás para que no se los roben del trabajo, las mamás cargan a sus hijos" (la disciplina)

15. Lupe, cuatro años

"Los juegos" (los juegos).

16. Karen, cinco años, preescolar

\section{(c) (i) (2)}

La Revista Estudios es editada por la Universidad de Costa Rica y se distribuye bajo una Licencia Creative Commons Atribución-NoComercial-CompartirIgual 3.0 Costa Rica. Para más información envíe un mensaje a revistaestudios.eeg@ucr.ac.cr. 
Dossier: V Simposio Internacional y IX Nacional sobre Derechos de la Niñez y la Adolescencia "Las muchachas vienen a platicar con la leche, cargan la leche. Los niños están debajo de la resbaladilla y los niños columpiándose...el niño que está enfermo" (a despensa, pláticas de nutrición, los juegos, el consultorio médico).

\section{Diagrama de redes}

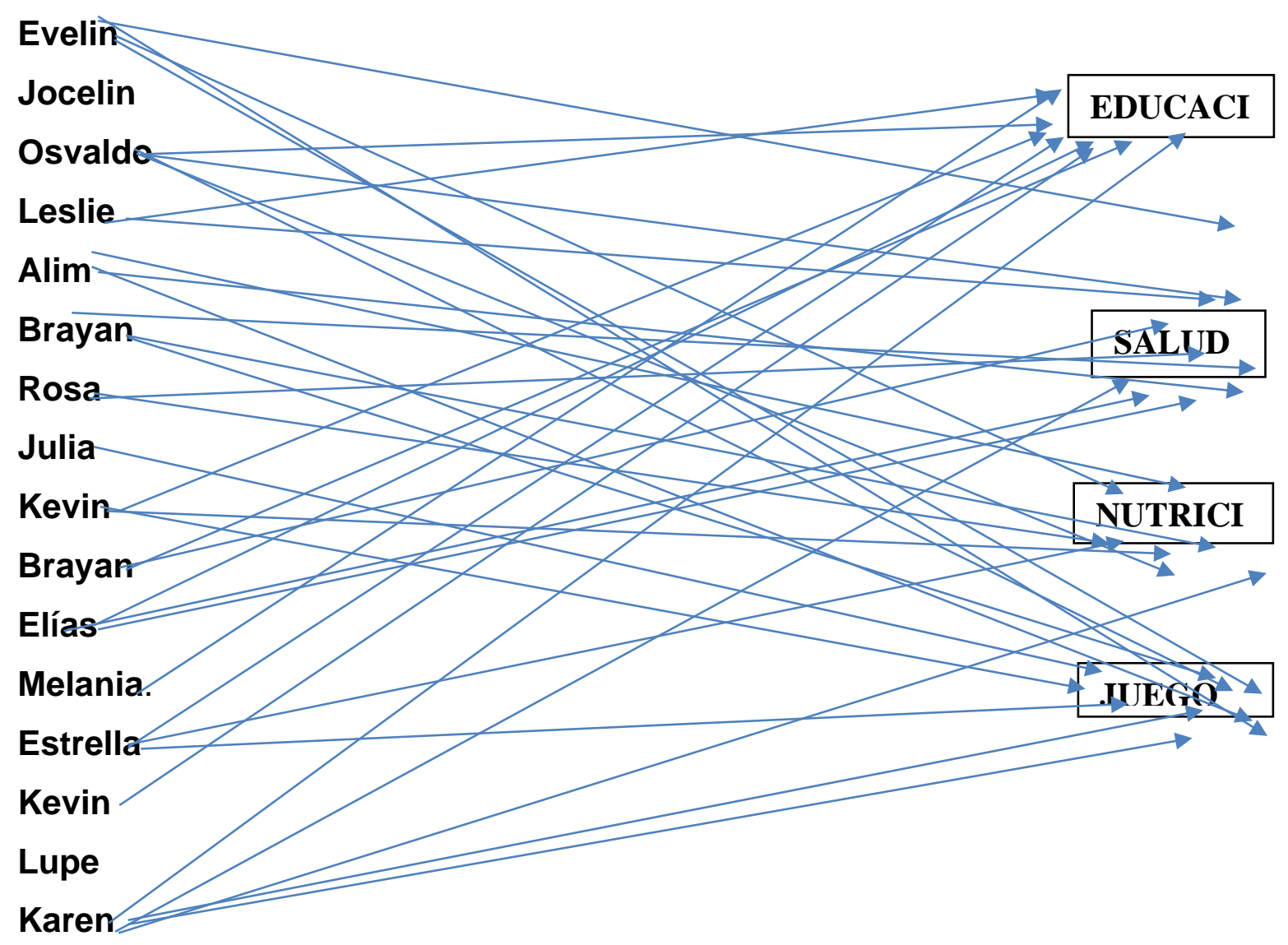

\section{c.) (i) (2)}

La Revista Estudios es editada por la Universidad de Costa Rica y se distribuye bajo una Licencia Creative Commons Atribución-NoComercial-CompartirIgual 3.0 Costa Rica. Para más información envíe un mensaje a revistaestudios.eeg@ucr.ac.cr. 
Dossier: V Simposio Internacional y IX Nacional sobre Derechos de la Niñez y la Adolescencia

\section{Análisis de resultados}

Estos registros traducen la voz de los propios niños e indican una mirada inclusiva en su participación, ahí donde su identidad social se ve fortalecida por sus interacciones y relaciones de producción del discurso en el contexto inmediato. Es la comunidad relacional descrita por de Donati (1993) quien refiere que el tiempo de la relación es emergente con una intensidad emocional que las mismas complejidades de sus redes facilitan (p. 48) Un espacio carente de herramientas para el entretenimiento infantil donde la disciplina es la estrategia más inmediata para evitar accidentes, un consultorio médico adaptado para consulta general aun cuando el registro mayor de consulta infantil refiere un 35\% con infecciones gastrointestinales y respiratorias en menores de 5 años.

Los datos describen un colectivo infantil en un contexto sociohistórico geográfico propio, donde los procesos son emergentes y ponen en discusión la institucionalización del desarrollo y la ciudadanía infantil en constante negociación bien sea con el llanto, el trabajo colectivo en familia para ayudar con la despensa familiar, compartir el espacio de juegos infantiles con otros niños, ayudar a la madre en el cuidado de los más pequeños , estos códigos se convierten en un intercambio simbólico que las mismas redes posibilitan.

En este estudio se pretende reformular el análisis de las políticas de infancia a partir de la teoría relacional para comprender la emergencia de colectivos infantiles como sujetos de derechos y agentes sociales que producen cambios como fruto de las interacciones en red de relaciones en una sociedad posmoderna. Lo anterior obedece a que no es posible estudiar el desarrollo infantil temprano y reducir su análisis desde una perspectiva evolutiva del desarrollo._sin embargo, las relaciones sociales configurado por las políticas de infancia son determinantes por los contextos colectivos preexistentes (relación laboral, familiares, políticos y culturales).

\section{(c) (i) (-)}

La Revista Estudios es editada por la Universidad de Costa Rica y se distribuye bajo una Licencia Creative Commons Atribución-NoComercial-CompartirIgual 3.0 Costa Rica. Para más información envíe un mensaje a 
Dossier: V Simposio Internacional y IX Nacional sobre Derechos de la Niñez y la Adolescencia

Los niños son sujetos productores de su propio desarrollo. Su manera de mirar, comprender y estar en el mundo les permite hacer de este espacio su lugar social de acción. Por consiguiente, el bienestar indica una reconstrucción de sus mismos códigos, es decir, no es el estado benefactor, ni el estado de derechos, es un estado negociador con alta interdependencia de sus relaciones con otros actores para otorgar los servicios, dentro de ellos el mercado, ahí donde los niños desarrollan nuevas prácticas de bienestar a través de otros agentes que las redes emergentes posibilitan, como lo es el programa "compartamos bancos"

\section{Conclusiones:}

La ciudadanía infantil es puesta en discusión a partir del principio del interés superior del niño, una frase literal que requiere más investigación para su incorporación en los programas sociales, al igual que el niño como sujeto de derecho. Estos datos indican que la ciudadanía depende de una condición de relación e interacción desde el momento que los niños están en contacto con otros actores que le brindan bines para su bienestar. En efecto, el capital social consiste en una red de relaciones comunitarias para erigirse así en un niño con capacidad de agenciamiento. Estos agentes niños adquieren su identidad social a partir de sus relaciones en los contextos de producción más inmediatos. Quizá, estos vínculos inmediatos contribuyen a su desarrollo y bienestar, es así, que dichas relaciones operan en red y producen un sistema de bienestar simbólico y emergente, ya que el niño le asigna significados y valor a dicho intercambio. Los niños son agentes de cambio y agentes activos en la transformación de su desarrollo, su disposición de explorar, actuar y valorarse como sujetos políticos en formación, desde el momento que el espacio de negociación es público con sus iguales y los adultos que ahí asisten.

La nueva sociología de la infancia requiere un planteamiento plural que responda a los diversos espacios donde están presente los niños como unidad de análisis, es 
Dossier: V Simposio Internacional y IX Nacional sobre Derechos de la Niñez y la Adolescencia decir, estos nuevos escenarios indican que la escuela, la familia están siendo trastocados por los nuevos acontecimientos globales. Por lo anterior son necesarias diversas herramientas para aproximarse a esta realidad. Para concluir, es posible que el enfoque relacional retoma a los niños como participantes competentes en el mundo social que ellos crean y recrean. Abordar a los niños en la investigación y conocer su perspectiva en conjunto de las acciones de los mismos adultos que están en relación con ellos, son los nuevos hallazgos que permiten hacer visibles las subjetividades de un sujeto en construcción.

\section{(c) (i) (2)}

La Revista Estudios es editada por la Universidad de Costa Rica y se distribuye bajo una Licencia Creative Commons Atribución-NoComercial-CompartirIgual 3.0 Costa Rica. Para más información envíe un mensaje a revistaestudios.eeg@ucr.ac.cr. 
Dossier: V Simposio Internacional y IX Nacional sobre Derechos de la Niñez y la Adolescencia

\section{Bibliografía.}

Cortina, A. (1997). Ciudadanos del mundo: hacia una teoría de la ciudadanía. Editorial: Alianza.

Donati, P. (1993). Pensamiento sociológico y cambio social: Hacia una teoría relacional. Revista española de investigaciones sociales (Reis) Núm. 63: p. 29-51 (23 pagina), publicado por Centro de Investigaciones sociológicas. España.

Gaitán, Muñoz L. (2006). La nueva sociología de la infancia. Aportaciones de una mirada distinta. Revista, Política y sociedad, Vol. 43, Núm. 1, Págs. 9-26. España.

Geertz, C. (2003). "Hacia una teoría interpretativa de las culturas". En Geertz, La interpretación de las culturas. Pags 17-19 Recuperado de https://d1watxts1xzle7.cloudfront.net/36426920/geertzclifford-

Granovetter, M. S. (2000). La tuerza de los vínculos débiles. Política y sociedad, Vol. 1, núm. 33. Recuperado en. https://revistas.ucm.es/index.php/POSO/issue/view/POSO000013

Guber, R. (2011). La etnografía: método, campo y reflexividad. Bogotá: Grupo Editorial, Norma.

Instituto Nacional de Estadística y Geografía (2011) Censo de población y vivienda 2010, recuperado en https://www.inegi.org.mx.

Lozarez C, C. (1996). La teoría de redes sociales. Papers: revista de sociología, (48) 103-126. http://dx.doi.org/10.5565/rev/papers/v48n0.1814

Mayal, B. (Jun-2000). The sociology of childhood in relation to children's rights. The International Journal of Children's Rights, 8(3), 243-259.recuperado de https://doi.org/10.1163/15718180020494640

Rodríguez, P. I. (2006). Redefiniendo el trabajo metodológico cualitativo con niños: el uso de la entrevista de grupo aplicada al estudio de la tecnología. Empírea. Revista de metodología de ciencias sociales, 12: pp. 65-88. Recuperado de DOI: https://doi.org/10.5944/empiria.12.2006.1135

\section{(c) (i) (9)}

La Revista Estudios es editada por la Universidad de Costa Rica y se distribuye bajo una Licencia Creative Commons Atribución-NoComercial-CompartirIgual 3.0 Costa Rica. Para más información envíe un mensaje a revistaestudios.eeg@ucr.ac.cr. 
Dossier: V Simposio Internacional y IX Nacional sobre Derechos de la Niñez y la Adolescencia

\section{Anexos.}

Listado de fotografías de apoyo en la entrevista grupal con niñas y niños Imagen \#1 Imagen \#2

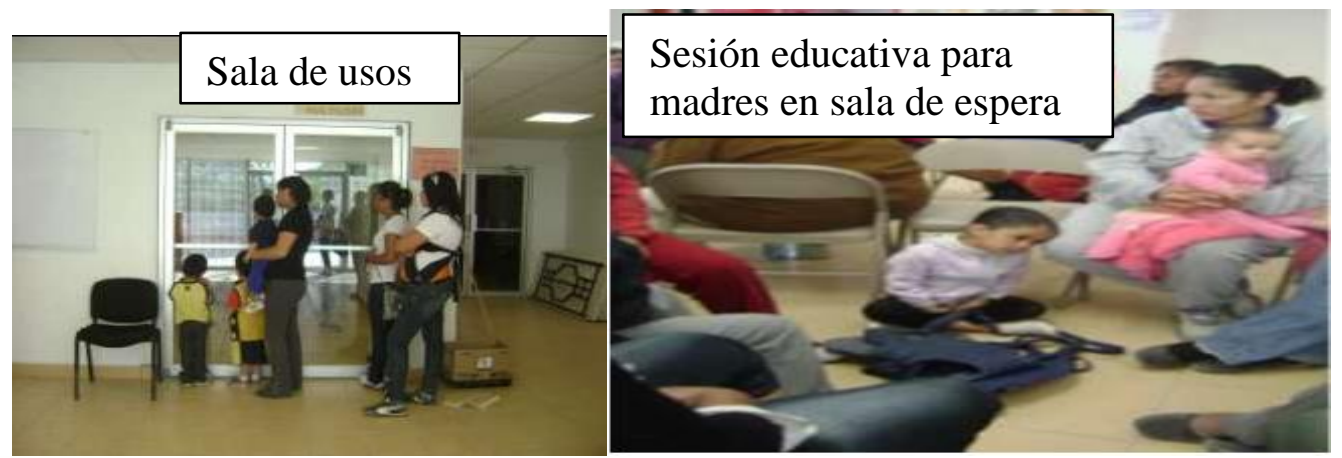

Imagen \#3

Imagen \#4

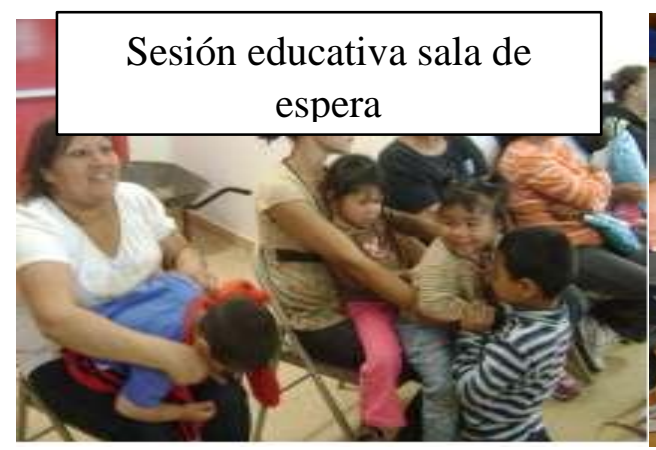

Sesión de aerobics para mujeres.

Imagen \#5

Imagen \#6

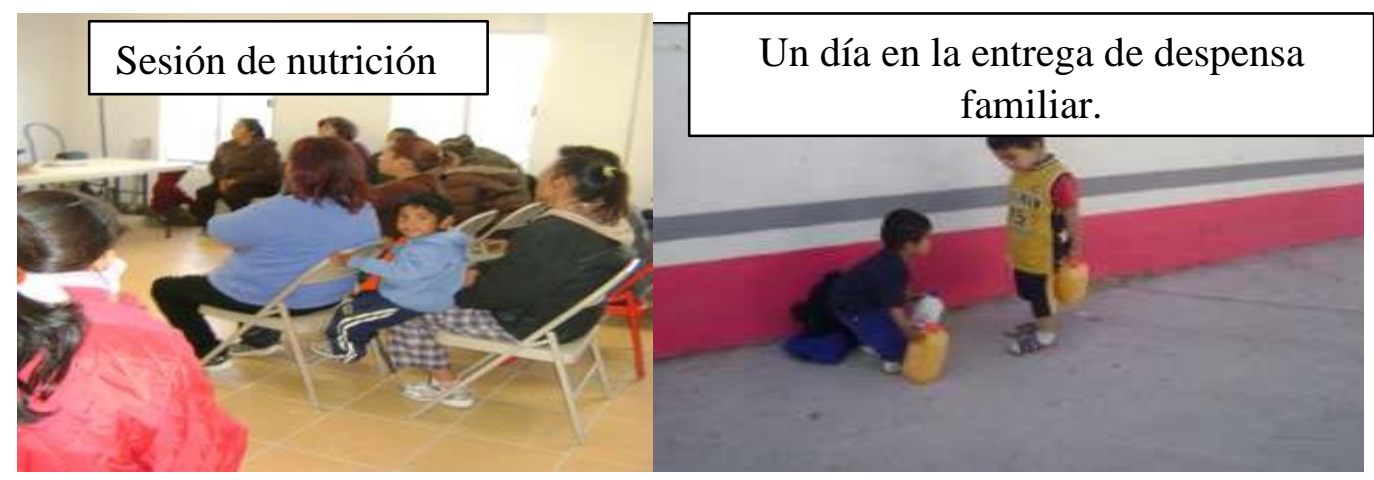

\section{(C) $(\otimes \odot \odot$}

La Revista Estudios es editada por la Universidad de Costa Rica y se distribuye bajo una Licencia Creative Commons Atribución-NoComercial-CompartirIgual 3.0 Costa Rica. Para más información envíe un mensaje a revistaestudios.eeg@ucr.ac.cr. 
Dossier: V Simposio Internacional y IX Nacional sobre Derechos de la Niñez y la Adolescencia

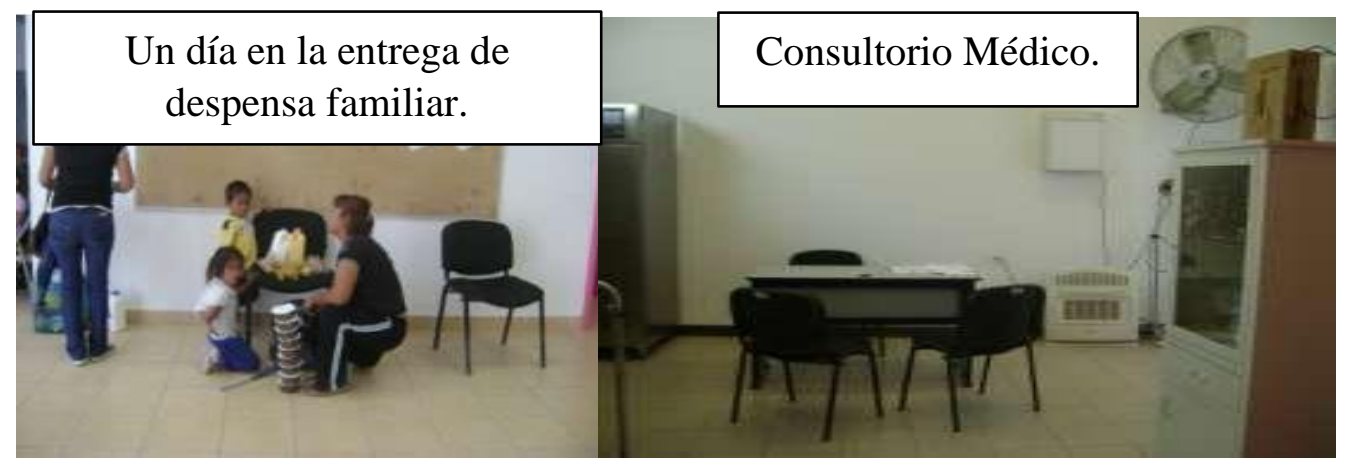

Imagen \#7

Imagen \#8

Imagen \#9

Imagen \#10

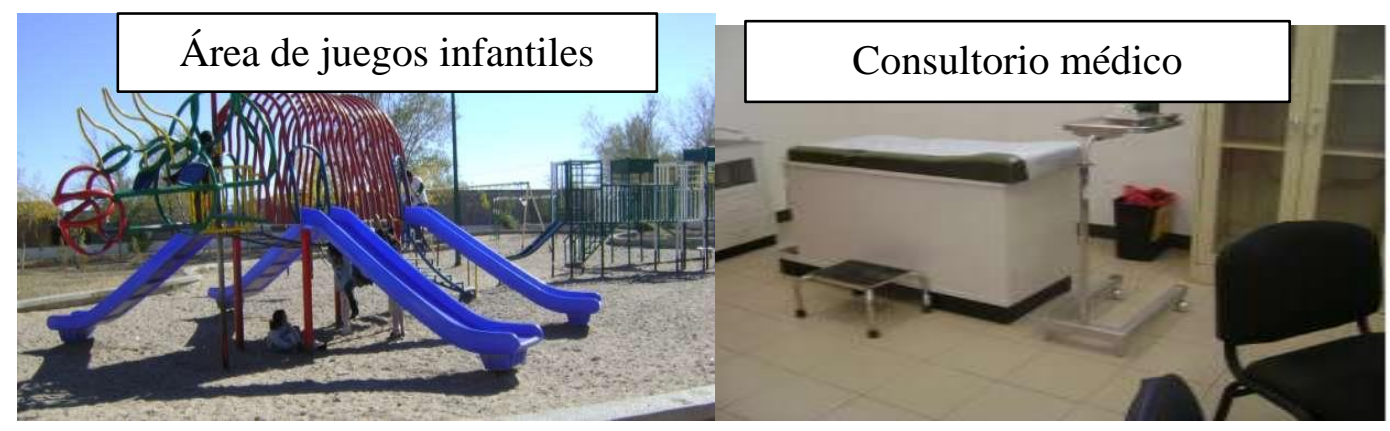

\section{(C) $(\Theta \odot \odot$}

La Revista Estudios es editada por la Universidad de Costa Rica y se distribuye bajo una Licencia Creative Commons Atribución-NoComercial-CompartirIgual 3.0 Costa Rica. Para más información envíe un mensaje a revistaestudios.eeg@ucr.ac.cr. 